\title{
The Preoperative Assessment and Optimization of Patients Undergoing Major Urological Surgery
}

\author{
Helen W. Cui ${ }^{1} \cdot$ Benjamin W. Turney ${ }^{1} \cdot$ John Griffiths $^{2}$
}

Published online: 6 June 2017

(C) The Author(s) 2017. This article is an open access publication
Abstract
Purpose of Review Improving patient outcomes from major urological surgery requires not only advancement in surgical technique and technology, but also the practice of patient-cen- tered, multidisciplinary, and integrated medical care of these patients from the moment of contemplation of surgery until full recovery. This review examines the evidence for recent developments in preoperative assessment and optimization that is of relevance to major urological surgery.
Recent Findings Current perioperative medicine recommen- dations aim to improve the short-term safety and long-term effectiveness of surgical treatments by the delivery of multi- disciplinary integrated medical care. New strategies to deliver this aim include preoperative risk stratification using a frailty index and cardiopulmonary exercise testing for patients un- dergoing intra-abdominal surgery (including radical cystectomy), preoperative management of iron deficiency and anemia, and preoperative exercise intervention.
Summary Proof of the utility and validity for improving surgical outcomes through advances in preoperative care is still evolving. Evidence-based developments in this
This article is part of the Topical Collection on Urosurgery
Helen W. Cui
helen.cui@nds.ox.ac.uk
Benjamin W. Turney
ben.turney@nds.ox.ac.uk
field are likely to benefit patients undergoing major uro- logical surgery, but further research targeted at high-risk patients undergoing specific urological operations is required.
Keywords Preoperative assessment · Urological surgery · CPET $\cdot$ Cystectomy $\cdot$ Nephrectomy $\cdot$ Nephroureterectomy

\begin{tabular}{|c|c|}
\hline Abbreviation & \\
\hline $\mathrm{ACC}$ & American College of Cardiologists \\
\hline ACS NSQIP & American College of Surgeons' \\
\hline & National Surgical Quality \\
\hline & Improvement Program \\
\hline AHA & American Heart Association \\
\hline ASA & American Association of \\
\hline & $\begin{array}{l}\text { Anaesthesiologists physical status } \\
\text { classification }\end{array}$ \\
\hline AT & Anaerobic threshold \\
\hline & (also known as lactate threshold) \\
\hline AUA & American Urology Association \\
\hline CI & Confidence interval \\
\hline CPET & Cardiopulmonary Exercise Test \\
\hline CSHA-FI & $\begin{array}{l}\text { Canadian Study of Health } \\
\text { and Aging Frailty Index }\end{array}$ \\
\hline EAU & European Association of Urology \\
\hline ERAS & Enhanced Recovery After Surgery \\
\hline ESA & European Society of Anaesthesiologists \\
\hline ESC & European Society of Cardiologists \\
\hline NCEPOD & $\begin{array}{l}\text { National Confidential Enquiry } \\
\text { into Patient Outcome and Death }\end{array}$ \\
\hline NICE & National Institute of Health and Care \\
\hline & Excellence \\
\hline PWC-170 & Physical Work Capacity cycle test \\
\hline $\mathrm{RCT}$ & Randomized Controlled Trial \\
\hline
\end{tabular}




\begin{tabular}{|c|c|}
\hline & $\begin{array}{l}\text { Systemic Inflammatory } \\
\text { Resnonse Syndrome }\end{array}$ \\
\hline & Response Syndrome \\
\hline SORT & $\begin{array}{l}\text { Surgical Outcome Risk } \\
\text { Tool }\end{array}$ \\
\hline UK & United Kingdom \\
\hline $\mathrm{VE} / \mathrm{VCO}_{2}$ & $\begin{array}{l}\text { Ventilatory equivalent } \\
\text { for carbon dioxide }\end{array}$ \\
\hline $\mathrm{V}_{2}$ & Oxygen consumption \\
\hline $6 \mathrm{MW}$ & 6 Min Walk Test \\
\hline
\end{tabular}

\section{Introduction}

The number of patients undergoing major urological surgery is growing. From 2011 to 2015, there has been an increase in the number of nephrectomies, radical cystectomies, and radical prostatectomies being performed in the UK by $9.5,8.5$, and 53\% respectively [1-5]. Improvements in surgical technique and technology [6], as well as intraoperative and postoperative care, [7] and enhanced recovery programs [8], have further reduced patient morbidity and mortality from major urological surgery.

However, the current and future patient populations undergoing major urological surgery is increasingly older with a greater number of associated medical comorbidities [9, 10]. A significant proportion of these patients therefore carry a greater risk of experiencing increased peri- and postoperative morbidity and mortality even before "knife-to-skin" occurs. Across the surgical specialties, there is increased recognition of the importance of preoperative assessment and perioperative medical care within the surgical pathway to evaluate and manage the patient above and beyond operation-specific issues [11]. A recent National Confidential Enquiry into Patient Outcome and Death (NCEPOD) report into perioperative care of surgical patients in the UK found that although "high-risk patients" only comprise $10 \%$ of the overall inpatient surgical workload, they account for $80 \%$ of deaths after surgery [12]. A key finding of the NCEPOD report was that preoperative assessment and intervention pathways play a vital role in both identifying and optimizing those patients at higher risk of morbidity and mortality after surgery [12].

Although the concept of preoperative medicine and its role in improving surgical outcomes is gaining wide recognition within the anesthetic literature and associated governing bodies [13-15], there is currently a relatively unmet need for similar recognition within the surgical literature and surgical governing bodies. A key recommendation of the Royal College of Anaesthetists Perioperative Medicine Vision Document is the importance of a true multidisciplinary perioperative team, with surgeons at the heart of it [13]. In the era of surgeonspecific outcome reporting, the role of the surgeon and close working with anesthetic colleagues is more important than ever, not just during the operation, but also in the pre- and postoperative period [16].

This review will consider the literature investigating the recent recommendations and developments in the field of preoperative assessment and preoperative interventions, and how this has been, or can be, applied to major urological surgery. Table 1 summarizes the main studies highlighted in this review.

\section{Preoperative Assessment}

A key aim of preoperative assessment is to use validated scoring systems and risk indices to identify patients at predicted higher risk of complications from surgery. Examples are the NCEPOD Surgical Outcome Risk Tool (SORT) [25, 26], The American College of Surgeons Mortality and Morbidity Risk Calculator [27], the P-POSSUM [28, 29], and the Lee's Cardiac Risk Index [30]. This can then guide not only the planning of surgery and perioperative care interventions, but also allow informed decision making with the patient, such that, in some cases, undertaking surgery may not be the best option. This is especially pertinent for those patients with prostate and bladder cancer that have the option of radiotherapy. Until recent times, this was largely determined by the surgeon's clinical acumen in being able to assess risk based on the "look" of a patient. However, current theories on how surgery impacts on patient physiology provide a more scientific approach for how patient factors can influence surgical outcome. Where higher-risk patients have been identified, the available time ahead of surgery can then be used to optimize and treat any relevant existing comorbidities and to make a detailed periand postoperative medical management plan for them [13].

\section{Preoperative Tests}

There is considerable variation in the preoperative assessment process between countries, and the surgical centers within countries [12]. There are numerous preoperative patient risk assessment indices that include subjective and objective questionnaires, scoring systems, and static and dynamic tests. However, to date, there is limited consensus on the efficacy or cost efficiency of these assessments [11]. Current guidelines from both the American Urological Association (AUA) and the European Association of Urology (EAU) provide few recommendations on the general preoperative assessment for major urological surgery. The AUA guidelines only offer recommendations with respect to anticoagulation management [31], and the EAU guidelines include an acknowledgement that the American Association of Anesthesiologists (ASA) grade can predict risk of major complications following radical cystectomy [32]. 


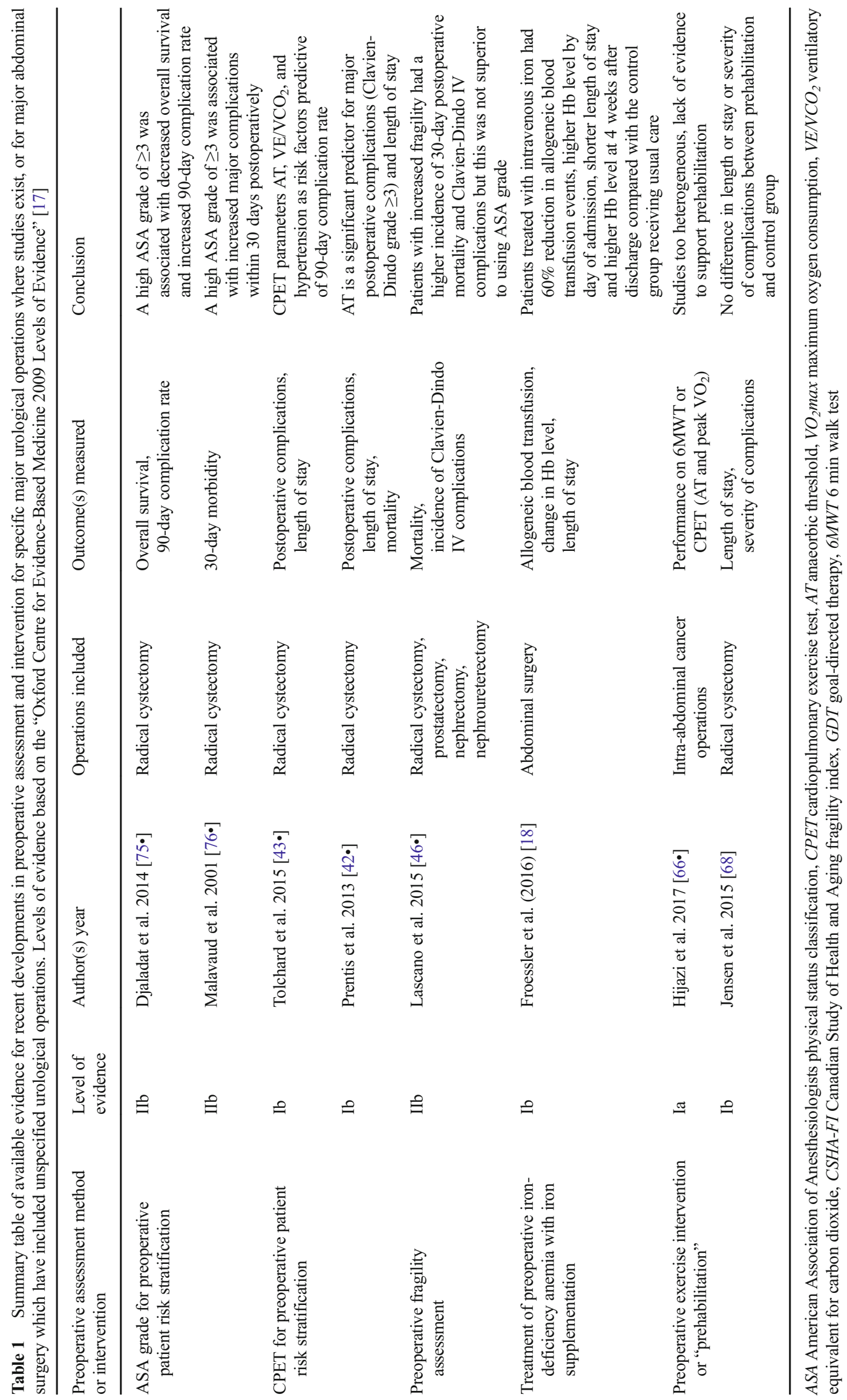


In the absence of surgical specialty-specific guidelines, the National Institute of Health and Care Excellence (NICE) [14] in the UK and the American Colleges of Cardiology, Radiology and Anaesthesiologists [33] offer general guidelines for preoperative testing, with consensus between their recommendations. Figure 1 offers a selected summary of these guidelines applicable to major urological surgery. Important principles are the need to fully investigate high-risk patients in preoperative assessment clinics [12]; the need to avoid excessive preoperative testing with the potential for spurious results, patient anxiety, delay to surgery and increased cost $[34,35]$; the need to review any results available from primary care to highlight issues and avoid unnecessary repetition [14]; and the need to follow specialized recommendations for patients with obesity and diabetes due to the increased risk of complications for these patient groups [36].

\section{Cardiopulmonary Exercise Testing}

Preoperative cardiopulmonary exercise testing (CPET) has been used for many years to quantify the exercise capacity of the patient [37]. Surgery is widely recognized as a physiological insult that results in a systemic inflammatory response syndrome (SIRS) [21]. Thus, the result of surgical insult is a globally increased tissue demand for oxygen delivery combined with a reduced ability for these tissues to extract oxygen, both during the inflammatory insult ("the surgery") and afterwards ("the recovery") [20]. This response can result in tissue oxygenation debt during recovery from the surgery phase, with subsequent adverse consequences on end-organ function and wound healing [38]. A surgical patient's exercise capacity tested during CPET reflects their ability to increase their cardiac output, and therefore oxygen delivery, to sufficiently meet the increased metabolic need of the postoperative phase, and this ability has been associated with improved survival after major surgery [39]. CPET has been shown to be able to identify those patients with a reduced capacity to cope with this increased oxygen demand and therefore identify the high-risk patient group for intraoperative and postoperative complications and delayed recovery from surgery [39, 40]. Decisions can then be made before surgery as to potential preoperative interventions to try and ameliorate this risk and to the level of care required postoperatively, for example, the need for high dependency (level 2) or intensive care (level 3) resources [12].

The largest preoperative CPET evidence base is currently in cardiothoracic surgery, but there is a growing interest for its utility in patients undergoing intra-abdominal surgery [22]. A recent NCEPOD report has shown that preoperative CPET is routinely undertaken in approximately $40 \%$ of UK hospitals as part of preoperative assessment of patients undergoing major surgery [13]. During a CPET, the patient is asked to exercise to their maximal effort on a treadmill or against increasing
Fig. 1 Flowchart of preoperative test selection relevant to major urological surgery based on current recommendations from the NICE [14]

resistance on a static exercise bike, with continuous ECG, blood pressure, oxygen saturation, and inspiratory and expiratory ventilatory gas monitoring. The exercise component of the test takes up to $15 \mathrm{~min}$, and combined with a full anesthetic consultation, a CPET clinic routinely lasts up to $1 \mathrm{~h}$.

CPET generates various parameters that characterize the patient's cardiorespiratory reserve and some of these parameters have been shown to prognosticate for postoperative mortality and morbidity across a range of operations. The two main CPET parameters cited in the current literature are the peak $\mathrm{VO}_{2}$ and the anaerobic threshold (AT) [41]. The peak $\mathrm{VO}_{2}$ is the maximum level of oxygen consumption the patient can achieve at maximal effort; the AT is the threshold of oxygen consumption at which aerobic respiration is supplemented by anaerobic respiration in order to eliminate excess carbon dioxide. Both parameters are expressed in milliliter/kilogram/ minute.

A review of the potential utility of CPET in identifying high-risk patients before intra-abdominal surgery has been recently published [22]. Heterogeneity of the data of the included 37 prognostic studies precluded a meta-analysis. A quantitative synthesis of the 10 studies which included patients undergoing a mixture of major abdominal surgeries (including 2 studies solely involving radical cystectomy patients) showed 4 studies reporting an AT of $<11 \mathrm{ml} / \mathrm{kg} / \mathrm{min}$ to be a significant predictor of postoperative mortality. However, one study showed AT was not a significant predictor of mortality, and of the two studies of CPET before radical cystectomy, one had an insufficient number of postoperative deaths and no statistical analysis for mortality [42•], and the other had an insufficient sample size [43•]. In terms of predicting postoperative morbidity, five studies of intra-abdominal surgery, including the two studies of radical cystectomy patients only, showed AT was again the strongest predictor. Of the radical cystectomy studies, Prentis and colleagues showed an AT $<12 \mathrm{ml} / \mathrm{kg} / \mathrm{min}$ to be predictive of in-hospital morbidity [42•], and Tolchard and colleagues showed a significantly different AT and peak $\mathrm{VO}_{2}$ between patients who experienced a Clavien-Dindo grade $\geq 2$ complication within 90 days postoperatively and those who did not [43•]. This systematic review suggests that different CPET parameters will have a varied relationship and predictive ability for different surgical interventions and clinical outcome measures. At the current time, there is no single threshold of one CPET parameter that can be used to stratify risk for surgery [22]. Further studies with adequate a priori sample size calculation and robust recording of standardized outcomes measures are therefore required to determine the true utility of CPET in predicting outcome from specific, major urological operations [22]. In 


\section{Patients over the age of 16 undergoing major complex surgery}

(not cardiothoracic or neurosurgery)

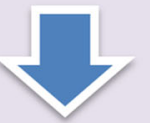

\section{All ASA Grades}

Take into account current medication to guide necessary tests, e.g. hemostasis for those on anticoagulation

- Microscopy and culture of a midstream urine sample

- $\quad$ Patients with diabetes: Recent HbA1c result from primary care

- Women of childbearing age: Consider pregnancy test

- Patients with a heart murmur and any cardiac symptom (including breathlessness, pre-syncope, syncope or chest pain) or signs or symptoms of heart failure: consider echocardiography after performing ECG and discussion with anesthetist

- Do not routinely offer: sickle cell testing or chest radiography

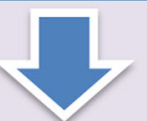

\section{Additional test by ASA Grade}

\section{ASA 1}

(normal healthy patient, non-smoking, no or minimal alcohol use)

\section{Full Blood Count}

Kidney Function Test

In patients over 65 with no ECG in the last 12 months: Consider ECG

ASA 2
(mild systemic disease including: current smoker, social alcohol drinker, obesity, well controlled diabetes or
hypertension, mild lung disease)
Full Blood Count
Kidney Function Test
ECG

ASA 3
$\begin{array}{r}\text { (severe systemic disease e.g. poorly controlled diabetes or hypertension, implanted pacemaker, patient on dialysis, } \\ \text { history of myocardial infarction or stroke) } \\ \text { or ASA } 4\end{array}$
$\begin{array}{r}\text { (severe systemic disease that is a constant threat to life e.g. myocardial infarction or stroke within the last } 3 \text { months, } \\ \text { severe heart failure) }\end{array}$
Full Blood Count
Kidney Function Test
ECG
Lung function test and arterial blood gas: discuss with anesthetist as soon as possible in patients with ASA
3 or 4 due to respiratory disease
In patients with chronic liver disease: consider checking hemostasis


addition to the value of the objective measures obtained during CPET, it is likely that the anesthetic review usually conducted as part of CPET clinic, which will include a review of comorbidities, medications, and formulation of a bespoke preoperative optimization plan contributes to the utility of CPET as a risk stratification tool.

\section{Frailty Assessment}

As well as formal cardiorespiratory assessment, there is growing evidence for the concept of patient "frailty" as an important risk factor for postoperative complications in the elderly population [44], which offers more information than using age alone. The Royal College of Anaesthetists in the UK recommends that extension of the multidisciplinary team to involve elderly care physicians should be considered for the preoperative assessment and management of patients aged 70 and over [13]. Frailty assessment takes into account an elderly patient's strength, energy, cognition, health status, speed of any functional decline, and the impact on their activities of daily living - leading to the concept of patient "vulnerability" [45]. The Canadian Study of Health and Aging Frailty Index (CSHA-FI) has been validated in the general elderly population to predict risk of death and institutionalization [45]. An abbreviated version of this score has been validated as a preoperative risk stratification tool across different surgical specialties [46•].

In 2005-2013, a large retrospective analysis of the outcomes of 41,681 patients that had undergone major urological cancer surgery was published [46 $]$. Urological procedures included prostatectomy, cystectomy, nephrectomy, and nephroureterectomy, and variables studied were a modified frailty index score consisting of 11 variables from the CSHA-FI, history of metastasis, chemotherapy or radiation exposure, weight loss, and renal failure. This retrospective analysis showed patients with a high modified frailty index score had a significantly higher odds of a Clavien-Dindo 4 event (OR $=3.70,95 \%$ CI 2.87 to 4.79$)$ and 30 day mortality ( $\mathrm{OR}=5.95,95 \% \mathrm{CI} 3.72$ to 9.51$)$ compared to nonfrail patients [46॰]. Although this modified frailty index was superior to the Charlson Comorbidity Index in predicting 30-day mortality and Clavien-Dindo 4 events, it was still not superior to using the ASA grade. As with other prognostic indicators that lack propensity adjustment, heterogeneity of both the operative intervention and the patient characteristics will affect the strength of the conclusions of how risk factors affect clinical outcomes. The heterogeneity of major urological operations included in this review may have affected the prognostic ability of the modified frailty index. For example, cystectomy patients had a 30-day mortality rate of $2.6 \%$ and Clavien-Dindo 4 complication rate of $9.5 \%$, whereas prostatectomy patients, as can be expected, had a lower 30-day mortality rate of only $0.2 \%$ and Clavien-Dindo 4 complication rate of $1.1 \%$. A separate analysis of 2679 cystectomy patients from the same database showed a similar predictive ability for the modified frailty index score to predict postoperative complications [24]. Two limitations of this analysis of cystectomy patients are the heterogeneity with respect to histological staging, exposure to neoadjuvant chemotherapy and type of urinary diversion performed, and the fact that the utility of the modified frailty index score was not compared to other validated risk stratification tools.

Although systematic preoperative frailty assessment of elderly patients has face validity, the additional utility of any individual frailty scoring system in predicting outcomes from specific urological operations needs further evaluation. Specifically, which components of a frailty scoring system can add value for mortality and morbidity risk stratification, over and above the stated ASA grade is unclear. Moreover, given the importance to the patient of longer-term health-related quality of life outcomes, such as functional outcome, future studies of prognostic indices need to incorporate these outcomes measures in addition to patient mortality and morbidity.

\section{Preoperative Intervention}

Established preoperative interventions in major urological surgery to try and improve cardiorespiratory reserve, and thus lessen surgical risk, include: optimization of patient comorbidities and related medications, optimization of nutritional status, and cessation of smoking [8]. New developments in preoperative intervention and optimization include evidence for the identification and treatment of anemia, and optimization of physiological reserve through preoperative exercise intervention.

\section{Preoperative Iron Deficiency and Anemia}

Patients scheduled for major urological cancer surgery are likely to have iron deficiency, with or without anemia. Iron deficiency is associated with approximately $43 \%$ of all malignancies [47], and the reported prevalence of preoperative anemia for patients undergoing radical prostatectomy is $8 \%$ [23], radical nephrectomy is $35 \%$ [48], nephroureterectomy is $39.7 \%$ [49], and radical cystectomy is $45 \%$ [50]. As part of the concept of better 'Patient Blood Management', is the growing evidence for early management of preoperative anemia using a multimodal and individualized approach, including treatment of preoperative anemia with iron supplementation, leading to a significant reduction of the need for perioperative allogeneic transfusion [18, 19, 47].

The significance of iron deficiency, and anemia, as a preoperative risk factor is supported by evidence that such patients have a higher rate of perioperative transfusion of blood products [51]. Allogeneic blood transfusion has immunosuppressive effects and, transfusion of a single unit of packed red blood cells has been associated with increased postoperative morbidity and mortality [52]. This detrimental effect of perioperative blood transfusion has also been demonstrated for 
patients undergoing radical cystectomy and prostatectomy $[53,54]$.

In patients undergoing major, non-cardiac surgery, preoperative anemia has recently been shown to be an independent risk factor for postoperative mortality and morbidity, in addition to the increased risk of need for transfusion [55, 56]. In one study of 684 patients undergoing radical cystectomy, preoperative anemia was found to be an independent predictor of disease recurrence, cancer-specific mortality, and all-cause mortality [57]. Of note, this study showed that although perioperative blood transfusion significantly increased all-cause mortality independent of preoperative anemia, those with preoperative anemia who received perioperative blood transfusion had no significant difference in outcome measures. The authors suggest that correction of preoperative anemia may have a survival benefit irrespective of reducing transfusion rate [57]. Preoperative anemia has also been found to be an independent predictor of cancer-specific mortality for patients undergoing radical nephrectomy [48] and nephroureterectomy [49]. These studies raise the possibility that the presence of preoperative anemia could be an important risk stratification tool for major urological surgery [48, 49, 57]. However, once the effect of its association with disease severity and other patient risk factors are accounted for, preoperative anemia in itself, is a relatively weak independent risk factor for poor surgical outcome [58].

As patients undergoing radical and partial nephrectomy, and radical cystectomy, have reported perioperative allogeneic transfusion rates of between 5-11\% [59] and 20-30\% [1, 60], respectively, targeting the preoperative management of anemia in these patients is likely to be of benefit. Intraoperative cell-salvage therapy during radical cystectomy has been shown to reduce the requirement for allogeneic transfusion [61], but no nephrectomy- or cystectomy-specific studies have been conducted regarding the preoperative management of anemia, and thus no recommendations have been made regarding preoperative anemia in a recent systematic review of enhanced recovery for urological surgery $[8,62]$.

In the absence of urology-specific guidelines, generic guidance can be taken from the 2017 "International Consensus Statement on the Perioperative Management of Anaemia and Iron Deficiency" [47]. This states that, for patients undergoing major surgery, where estimated blood loss is $>500 \mathrm{ml}$, treatment of iron deficiency with, or without anemia, is recommended. Treatment should be with oral iron supplementation (or intravenous iron supplementation for those unable to tolerate oral or who have $<6$ weeks before surgery) to achieve $\mathrm{aHb}$ of $>13 \mathrm{~g} / \mathrm{dl}$ in both sexes, with the primary aim to reduce transfusion rate and thereby improve outcomes from surgery $[18,47,63]$. However, to date, no Level 1 evidence exists as to whether improving $\mathrm{Hb}$ levels preoperatively, can significantly impact the postoperative morbidity and mortality rates beyond that which is associated with the increased risk of transfusion [47]. Results are awaited from an ongoing, multi-center, UK RCT on the effectiveness and cost-effectiveness of preoperative intravenous iron supplementation in reducing transfusion rate, length of stay, and postoperative complication rate [64].

\section{Preoperative Exercise Intervention}

It is hypothesized that better physical fitness preoperatively improves a patient's ability to meet the increased oxygen demand during and after surgery. Preoperative physical activity or exercise has been shown to improve a patient's peri- and postoperative ability to extract oxygen and tolerate the ischaemic conditions of surgery, which lessens the impact of any deficit in oxygen delivery [38]. Randomized controlled trials (RCTs) have been conducted in a variety of surgical populations to investigate the efficacy of preoperative exercise intervention as a form of preoperative rehabilitation or "prehabilitation" $[65,66 \bullet, 67]$. There is now embryonic evidence for "prehabilitation" in patients undergoing major urological surgery in the form of one completed RCT [68].

Jensen and colleagues conducted a RCT of preoperative exercise intervention in 107 patients undergoing radical cystectomy [68]. In addition to standard care, the intervention group received 2 weeks of preoperative training involving a twice daily home exercise program on a step trainer (provided by the hospital to the patient's home) and six different muscle strength and endurance exercises. The intervention also comprised of a postoperative phase of 1 week of in-hospital exercises and mobilization supervised by a physiotherapist. The standard of care was based on existing Enhanced Recovery After Surgery (ERAS) principles. Both the control and intervention groups received either robotic-assisted radical cystectomy or a minilaparotomy and urinary diversion based preoperatively on patient characteristics and preference. Compliance to the prehabilitation program (defined as completion of at least $75 \%$ of the program) was found to be 59\% and was checked by a phone call after 1 week. There was no significant difference in both length of stay as the primary outcome, or severity of complications as the secondary outcome, between the intervention and control groups [68]. It is postulated that the lack of effect shown by the prehabilitation intervention could be due to a number of factors that include too short a preoperative intervention time of 2 weeks; the use of less invasive methods of radical cystectomy and good application of ERAS principles that delivered a general reduction in length of stay and complication severity; and difficulties of investigator supervision to the home exercise program with possible poor overall patient compliance [68].

The most recent systematic review of prehabilitation in intraabdominal cancer surgery was published earlier this year by Hijazi and colleagues, and includes the study of radical cystectomy patients by Jensen and colleagues [66 $6^{\bullet}$. This systematic review undertook qualitative synthesis of seven RCTs and two prospective, non-randomized trials. In line with previously published systematic reviews [69-71] in this area, Hijazi and colleagues concluded that, at the current time, there is limited 
evidence that preoperative prehabilitation leads to a clinically significant physiologic improvement in patients undergoing major elective abdominal surgery [66 $]$. The lack of significant clinical effect from prehabilitation is likely to be due to a variety of factors that include lack of adherence to the individual exercise program, uncertainty and variation as to the ideal physiologic endpoint to measure, uncertainty as to the gold-standard components of a prehabilitation program, uncertainty as to the optimal preoperative duration of the prehabilitation program, and uncertainty as to which groups of patients and/or surgical procedures (e.g., open versus laparoscopic) would benefit most from a prehabilitation program $[66 \cdot 69]$.

A major criticism of existing prehabilitation trials is the lack of patient risk stratification in selection for inclusion into an individual trial [69]. A variety of validated tools are available that can predict those patients at higher risk of experiencing poorer surgical outcomes [11,12]. As patients predicted to be at higher risk are most likely to benefit from prehabilitation, a more rigorous approach would be to use a validated screening tool to risk stratify higher-risk patients into prehabilitation programs.

A major challenge in conducting studies of preoperative interventions remains the ability to demonstrate a significant difference in important clinical outcomes such as length of stay, major postoperative complications, and mortality. To date, studies are often not adequately powered to detect significant differences in these clinical outcomes, given that the rates of major complications and mortality remain low. When faced with a comorbid elderly population undergoing a range of intraabdominal operations, both open and laparoscopic, benign and oncological, there is currently no single preoperative intervention that has been shown to lead to an improvement in both clinical outcomes and quality of life outcomes [72]. Hence, the approach needs to be multidisciplinary and multimodal $[68,73]$. Future trials of separate individual components of prehabilitation are unlikely to show clear benefits in clinical outcomes, and the future direction of research in this area should be based on the concept of implementing a perioperative care pathway that is an aggregation of marginal gains $[13,74]$.

\section{Conclusion}

Few would argue against the fact that optimal, evidence-based, coordinated, preoperative assessment and intervention leads to improved outcomes from surgery. The challenge is being able to demonstrate the improvement in research studies, particularly randomized controlled trials. High-level evidence supporting the use of certain preoperative assessment tests and interventions is difficult to generate - due in part to the complex nature of the surgical process itself. To date, novel preoperative processes have been investigated and implemented, but despite having good face validity, clear effects of these processes on important clinical outcomes remain limited. However, the evidence base for how to further reduce surgical risk, and improve outcomes from surgery through preoperative assessment and intervention, is still in its infancy. For patients undergoing major urological surgery, it remains possible that accurate risk stratification through the use of preoperative CPET and frailty indices, in addition to an evidence-based approach to prehabilitation and the management of preoperative anemia, will be shown to lead to improved, clinically significant surgical outcomes.

\section{Compliance with Ethical Standards}

Conflict of Interest Helen W. Cui, Benjamin W. Turney, and John Griffiths each declare no potential conflicts of interest.

Human and Animal Rights and Informed Consent This article does not contain any studies with human or animal subjects performed by any of the authors.

Open Access This article is distributed under the terms of the Creative Commons Attribution 4.0 International License (http:// creativecommons.org/licenses/by/4.0/), which permits unrestricted use, distribution, and reproduction in any medium, provided you give appropriate credit to the original author(s) and the source, provide a link to the Creative Commons license, and indicate if changes were made.

\section{References}

Papers of particular interest, published recently, have been highlighted as:

- Of importance

1. BAUS. BAUS cystectomy outcomes data: summary \& timescale of the data [Internet]. British Association of Urological Surgeons. 2016a. [cited 2017 Feb 20]. Available from: http://www.baus.org. uk/patients/surgical_outcomes/cystectomy/timescales.aspx.

2. BAUS. BAUS nephrectomy outcomes data: summary and timescale of the data. 2016b. Available from: http://www.baus.org.uk/ patients/surgical_outcomes/nephrectomy/timescales.aspx.

3. British Association of Urological Surgeons. BAUS radical prostatectomy outcomes data: summary and timescale of the data [Internet]. British Association of Urological Surgeons. 2016. Available from: http://www.baus.org.uk/patients/surgical_ outcomes/radical prostatectomy/timescales.aspx.

4. Cresswell J, Mariappan P, Thomas SA. Radical cystectomy: analysis of trends in UK practice 2004-2012, from the British Association of Urological Surgeons' (BAUS) section of oncology dataset. J Clin Urol. 2016;9(1):49-56.

5. Laird A, Fowler S, Good DW, Stewart GD, Srinivasan V, Cahill D, et al. Contemporary practice and technique-related outcomes for radical prostatectomy in the UK: a report of national outcomes. BJU Int. 2015;115(5):753-63.

6. Koch MO. Robotic versus open prostatectomy: end of the controversy. J Urol. 2016;196(1):9-10.

7. Pillai P, McEleavy I, Gaughan M, Snowden C, Nesbitt I, Durkan G, et al. A double-blind randomized controlled clinical trial to assess the effect of Doppler optimized intraoperative fluid management on outcome following radical cystectomy. J Urol. 2011;186(6):2201-6.

8. Azhar RA, Bochner B, Catto J, Goh AC, Kelly J, Patel HD, et al. Enhanced recovery after urological surgery: a contemporary systematic review of outcomes, key elements, and research needs. Eur Urol. 2016;70(1):176-87. 
9. Mendoza D, Newman RC, Albala D, Cohen MS, Tewari A, Lingeman $\mathrm{J}$, et al. Laparoscopic complications in markedly obese urologic patients (a multi-institutional review). Urology. 1996;48(4):562-7.

10. Hamel MB, Henderson WG, Khuri SF, Daley J. Surgical outcomes for patients aged 80 and older: morbidity and mortality from major noncardiac surgery. J Am Geriatr Soc. 2005;53(3):424-9.

11. García-Miguel FJ, Serrano-Aguilar PG, López-Bastida J. Preoperative assessment. Lancet. 2003;362(9397):1749-57.

12. Findley GP. Knowing the risk: a review of the peri-operative care of surgical patients. National Confidential Enquiry into Patient Outcome and Death; London. 2011.

13. Mythen M. Perioperative medicine: the pathway to better surgical care [Internet]. The Royal College of Anaethetists. 2014. Available from: https://www.rcoa.ac.uk/sites/default/files/PERIOP-2014.pdf.

14. Routine preoperative tests for elective surgery (NICE Guideline NG45). National Institute for Health and Care Excellence. 2016. Available from: https://www.nice.org.uk/guidance/ng45.

15. Fleisher LA, Beckman JA, Brown KA, Calkins H, Chaikof EL, Fleischmann KE, et al. ACC/AHA 2007 guidelines on perioperative cardiovascular evaluation and care for noncardiac surgery: a report of the American College of Cardiology/American Heart Association Task Force on Practice Guidelines (writing committee to revise the 2002 guidelines on perioperative cardiovascular evaluation for noncardiac surgery) developed in collaboration with the American Society of Echocardiography, American Society of Nuclear Cardiology, Heart Rhythm Society, Society of Cardiovascular Anesthesiologists, Society for Cardiovascular Angiography and Interventions, Society for Vascular Medicine and Biology, and Society for Vascular Surgery. J Am Coll Cardiol. 2007;50(17):e159-242.

16. Bridgewater B. Patient-facing data is essential in the digital era: as surgeons we must take responsibility for our patients, and for our outcomes. The Bulletin of the Royal College of Surgeons of England. 2015;97(4):160-3.

17. The Oxford Levels of Evidence 1 [Internet]. Centre for EvidenceBased Medicine. OCEBM Levels of Evidence Working Group, Oxford Centre for Evidence-Based Medicine. 2009. Available from: http://www.cebm.net/oxford-centre-evidence-basedmedicine-levels-evidence-march-2009/.

18. Froessler B, Palm P, Weber I, Hodyl NA, Singh R, Murphy EM. The important role for intravenous iron in perioperative patient blood management in major abdominal surgery: a randomized controlled trial. Ann Surg. 2016;264(1):41-6.

19. Shander A, Van Aken H, Colomina MJ, Gombotz H, Hofmann A, Krauspe R, et al. Patient blood management in Europe. Br J Anaesth. 2012;109(1):55-68

20. Older P, Smith R. Experience with the preoperative invasive measurement of haemodynamic, respiratory and renal function in 100 elderly patients scheduled for major abdominal surgery. Anaesth Intensive Care. 1988;16(4):389-95.

21. Desborough JP. The stress response to trauma and surgery. Br J Anaesth. 2000;85(1):109-17.

22. Moran J, Wilson F, Guinan E, McCormick P, Hussey J, Moriarty J. Role of cardiopulmonary exercise testing as a risk-assessment method in patients undergoing intra-abdominal surgery: a systematic review. Br J Anaesth. 2016;116(2):177-91.

23. Muñoz M, Laso-Morales MJ, Gómez-Ramírez S, Cadellas M, Núñez-Matas MJ, García-Erce JA. Pre-operative haemoglobin levels and iron status in a large multicentre cohort of patients undergoing major elective surgery. Anaesthesia (Online). 2017b. Available from: http://onlinelibrary.wiley.com/doi/10.1111/anae.13840/full.

24. Chappidi MR, Kates M, Patel HD, Tosoian JJ, Kaye DR, Sopko NA, et al. Frailty as a marker of adverse outcomes in patients with bladder cancer undergoing radical cystectomy. Urol Oncol. 2016;34(6):256.e1-6.
25. The UCL/UCLH Surgical Outcomes Research Centre (SOuRCe) and The National Confidential Enquiry into Patient Outcome and Death (NCEPOD). NCEPOD Surgical Outcome Risk Tool [Internet]. SORT Surgery. 2014. Available from: http://www.sortsurgery.com

26. Protopapa KL, Simpson JC, Smith NCE, Moonesinghe SR. Development and validation of the Surgical Outcome Risk Tool (SORT). Br J Surg. 2014;101(13):1774-83.

27. American College of Surgeons National Surgical Quality Improvement Program. The American College of Surgeons National Surgery Quality Improvement Program Mortality and Morbidity Risk Calculator [Internet]. ACS NSQIP Surgical Risk Calculator. 2014. [cited february 1 2017]. Available from: http:/ riskcalculator.facs.org/RiskCalculator/.

28. Prytherch DR, Whiteley MS, Higgins B, Weaver PC, Prout WG, Powell SJ. P-POSSUM Score Calculator [Internet]. Risk Prediction in Surgery. 1998a. Available from: http://www.riskprediction.org. uk/index-pp.php

29. Prytherch DR, Whiteley MS, Higgins B, Weaver PC, Prout WG, Powell SJ. POSSUM and Portsmouth POSSUM for predicting mortality. Br J Surg. 1998b;85(9):1217-20.

30. Lee TH, Marcantonio ER, Mangione CM, Thomas EJ, Polanczyk $\mathrm{CA}$, Cook EF, et al. Derivation and prospective validation of a simple index for prediction of cardiac risk of major noncardiac surgery. Circulation. 1999;100(10):1043-9.

31. Culkin DJ, Exaire EJ, Green D, Soloway MS, Gross AJ, Desai MR, White JR, Lightner D. Anticoagulation and antiplatelet therapy in urologic practice: ICUD and AUA review paper. American Urological Association. 2014. Available from: https://www.auanet. org/education/guidelines/anticoagulation-antiplatelet-therapy.cfm.

32. van der Heijden MJ. Ribal JAWECNCCGGTLAG. Muscleinvasive and metastatic bladder cancer [Internet]. European Association of Urology. 2016. Available from: http://uroweb.org/ guideline/bladder-cancer-muscle-invasive-and-metastatic/.

33. Feely MA, Collins CS, Daniels PR, Kebede EB, Jatoi A, Mauck KF. Preoperative testing before noncardiac surgery: guidelines and recommendations. Am Fam Physician. 2013;87(6):414-8.

34. Katz RI, Dexter F, Rosenfeld K, Wolfe L, Redmond V, Agarwal D, et al. Survey study of anesthesiologists' and surgeons' ordering of unnecessary preoperative laboratory tests. Anesth Analg. 2011;112(1):207-12.

35. Munro J, Booth A, Nicholl J. Routine preoperative testing: a systematic review of the evidence. Health Technol Assess. 1997;1(12): i-iv. 1-62

36. O'neill F, Carter E, Pink N, Smith I. Routine preoperative tests for elective surgery: summary of updated NICE guidance. BMJ: $\mathrm{Br}$ Med J (Online). 2016;354. Available from: doi:10.1136/bmj.i3292.

37. Older P, Smith R, Courtney P, Hone R. Preoperative evaluation of cardiac failure and ischemia in elderly patients by cardiopulmonary exercise testing. Chest. 1993;104(3):701-4.

38. Lugo G, Arizpe D, Dominguez G, Ramirez M, Tamariz O. Relationship between oxygen consumption and oxygen delivery during anesthesia in high-risk surgical patients. Crit Care Med. 21:64-9.

39. Davies SJ, Wilson R. Preoperative optimization of the high-risk surgical patient. Br J Anaesth [Internet]. 2004. Available from: http://bja.oxfordjournals.org/content/93/1/121.short.

40. Older P, Hall A. Clinical review: how to identify high-risk surgical patients. Crit Care. 2004;8(5):369-72.

41. American Thoracic Society, American College of Chest Physicians. ATS/ACCP statement on cardiopulmonary exercise testing. Am J Respir Crit Care Med. 2003;167(2):211-77.

42. Prentis JM, Trenell MI, Vasdev N, French R, Dines G, Thorpe A, et al. Impaired cardiopulmonary reserve in an elderly population is related to postoperative morbidity and length of hospital stay after radical cystectomy. BJU Int. 2013;112(2):E13-9. Available evidence for recent developments in preoperative assessment and intervention. 
43. Tolchard S, Angell J, Pyke M, Lewis S, Dodds N, Darweish A, et al. Cardiopulmonary reserve as determined by cardiopulmonary exercise testing correlates with length of stay and predicts complications after radical cystectomy. BJU Int. 2015;115(4):554-61. Available evidence for recent developments in preoperative assessment and intervention.

44. Saxton A, Velanovich V. Preoperative frailty and quality of life as predictors of postoperative complications. Ann Surg. 2011;253(6): 1223-9.

45. Rockwood K, Song X, MacKnight C, Bergman H, Hogan DB, McDowell I, et al. A global clinical measure of fitness and frailty in elderly people. CMAJ. 2005;173(5):489-95.

46. Lascano D, Pak JS, Kates M, Finkelstein JB, Silva M, Hagen E, et al. Validation of a frailty index in patients undergoing curative surgery for urologic malignancy and comparison with other risk stratification tools. Urologic Oncology: Seminars and Original Investigations. 2015;33(10):426.e1-426.e12. Available evidence for recent developments in preoperative assessment.

47. Muñoz M, Acheson AG, Auerbach M, Besser M, Habler O, Kehlet $\mathrm{H}$, et al. International consensus statement on the peri-operative management of anaemia and iron deficiency. Anaesthesia. 2017a;72(2):233-47.

48. Magera Jr JS, Leibovich BC, Lohse CM, Sengupta S, Cheville JC, Kwon ED, et al. Association of abnormal preoperative laboratory values with survival after radical nephrectomy for clinically confined clear cell renal cell carcinoma. Urology. 2008;71(2):278-82.

49. Rink M, Sharifi N, Fritsche H-M, Aziz A, Miller F, Kluth LA, et al. Impact of preoperative anemia on oncologic outcomes of upper tract urothelial carcinoma treated with radical nephroureterectomy. J Urol. 2014;191(2):316-22.

50. Chang SS, Smith Jr JA, Wells N, Peterson M, Kovach B, Cookson MS. Estimated blood loss and transfusion requirements of radical cystectomy. J Urol. 2001;166(6):2151-4.

51. Wu W-C, Smith TS, Henderson WG, Eaton CB, Poses RM, Uttley G, et al. Operative blood loss, blood transfusion, and 30-day mortality in older patients after major noncardiac surgery. Ann Surg. 2010;252(1):11-7.

52. Ferraris VA, Davenport DL, Saha SP, Austin PC, Zwischenberger JB. Surgical outcomes and transfusion of minimal amounts of blood in the operating room. Arch Surg. 2012;147(1):49-55.

53. Matulay JT, Sui W, Onyeji I, James MB, Velez MC, DeCastro GJ. MP08-01 perioperative blood transfusion and radical prostatectomy: analysis of the National Surgical Quality Improvement Program database. J Urol. 2016;195(4):e85.

54. Linder BJ, Frank I, Cheville JC, Tollefson MK, Thompson RH, Tarrell RF, et al. The impact of perioperative blood transfusion on cancer recurrence and survival following radical cystectomy. Eur Urol. 2013;63(5):839-45.

55. Musallam KM, Tamim HM, Richards T, Spahn DR, Rosendaal FR, Habbal A, et al. Preoperative anaemia and postoperative outcomes in non-cardiac surgery: a retrospective cohort study. Lancet. 2011;378(9800):1396-407.

56. Baron DM, Hochrieser H, Posch M, Metnitz B, Rhodes A, Moreno $\mathrm{RP}$, et al. Preoperative anaemia is associated with poor clinical outcome in non-cardiac surgery patients. $\mathrm{Br} \mathrm{J}$ Anaesth. 2014;113(3):416-23.

57. Gierth M, Mayr R, Aziz A, Krieger S, Wullich B. Preoperative anemia is associated with adverse outcome in patients with urothelial carcinoma of the bladder following radical cystectomy. J Cancer Res Clin Oncol. 2015;141:1819-26.

58. Saager L, Turan A, Reynolds LF, Dalton JE, Mascha EJ, Kurz A. The association between preoperative anemia and 30-day mortality and morbidity in noncardiac surgical patients. Anesth Analg. 2013;117(4):909-15.

59. Henderson JM, Fowler S, Joyce A, Dickinson A, Keeley FX. Perioperative outcomes of 6042 nephrectomies in 2012: surgeonreported results in the UK from the British Association of
Urological Surgeons (BAUS) nephrectomy database. BJU Int. 2015;115:121-6.

60. Smith J, Pruthi RS, McGrath J. Enhanced recovery programmes for patients undergoing radical cystectomy. Nat Rev Urol. 2014;11(8): 437-44.

61. Aning J, Dunn J, Daugherty M, Mason R, Pocock R, Ridler B, et al. Towards bloodless cystectomy: a 10-year experience of intraoperative cell salvage during radical cystectomy. BJU Int. 2012;110(11b):E608-13.

62. Young MJ, Noon AP. Re: the important role for intravenous iron in perioperative patient blood management in major abdominal surgery: a randomized controlled trial. Eur Urol. 2017;71(4):690-1.

63. Bisbe E, García-Erce JA, Díez-Lobo AI, Muñoz M. A multicentre comparative study on the efficacy of intravenous ferric carboxymaltose and iron sucrose for correcting preoperative anaemia in patients undergoing major elective surgery. Br J Anaesth. 2011;107(3):477-8.

64. Richards T, Clevenger B, Keidan J, Collier T, Klein AA, Anker SD, et al. PREVENTT: preoperative intravenous iron to treat anaemia in major surgery: study protocol for a randomised controlled trial. Trials. 2015;16:254.

65. Carli F, Charlebois P, Stein B, Feldman L, Zavorsky G, Kim DJ, et al. Randomized clinical trial of prehabilitation in colorectal surgery. Br J Surg. 2010;97(8):1187-97.

66. Hijazi Y, Gondal U, Aziz O. A systematic review of prehabilitation programs in abdominal cancer surgery. Int J Surg. 2017;39:156-62. Available evidence for recent developments in preoperative assessment and intervention.

67. Carli F, Zavorsky GS. Optimizing functional exercise capacity in the elderly surgical population. Curr Opin Clin Nutr Metab Care. 2005;8(1):23-32.

68. Jensen BT, Petersen AK, Jensen JB, Laustsen S, Borre M. Efficacy of a multiprofessional rehabilitation programme in radical cystectomy pathways: a prospective randomized controlled trial. Scand J Urol. 2015;49(2):133-41.

69. Pouwels S, Stokmans RA, Willigendael EM, Nienhuijs SW, Rosman C, van Ramshorst B, et al. Preoperative exercise therapy for elective major abdominal surgery: a systematic review. Int J Surg. 2014;12(2):134-40.

70. Lemanu DP, Singh PP, MacCormick AD, Arroll B, Hill AG. Effect of preoperative exercise on cardiorespiratory function and recovery after surgery: a systematic review. World J Surg. 2013;37(4):71120.

71. Valkenet K, van de Port IGL, Dronkers JJ, de Vries WR, Lindeman E, Backx FJG. The effects of preoperative exercise therapy on postoperative outcome: a systematic review. Clin Rehabil. 2011;25(2): 99-111.

72. Audisio RA, Bozzetti F, Gennari R, Jaklitsch MT, Koperna T, Longo WE, et al. The surgical management of elderly cancer patients: recommendations of the SIOG surgical task force. Eur J Cancer. 2004;40(7):926-38.

73. Kehlet H, Wilmore DW. Multimodal strategies to improve surgical outcome. Am J Surg. 2002;183(6):630-41.

74. Durrand JW, Batterham AM, Danjoux GR. Pre-habilitation (i): aggregation of marginal gains. Anaesthesia. 2014;69:399-419.

75. Djaladat H, Bruins HM, Miranda G, Cai J, Skinner EC, Daneshmand S. The association of preoperative serum albumin level and American Society of Anesthesiologists (ASA) score on early complications and survival of patients undergoing radical cystectomy for urothelial bladder cancer. BJU Int. 2014;113(6): 887-93. Available evidence for recent developments in preoperative assessment and intervention.

76. Malavaud B, Vaessen C, Mouzin M, Rischmann P, Sarramon JP, Schulman C. Complications for radical cystectomy. Eur Urol. 2001;39(1):79-84. Available evidence for recent developments in preoperative assessment and intervention. 